\title{
Occupational Stress and Work Ability Among Nurses in an Academic Hospital
}

\author{
Das $\mathrm{SR}^{1 *}$, Biswas $\mathrm{C}^{2}$, Raza $\mathrm{AKMM}^{3}$, Akhtar $\mathrm{K}^{4}$, Kawsar $\mathrm{AA}^{5}$, Hossain $\mathrm{S}^{6}$ \\ ${ }^{1}$ Department of Community Medicine, Z H Sikder Women Medical College, Dhaka,Bangladesh; ${ }^{2}$ Upazilla \\ Health Complex, Dhamrai, Dhaka,Bangladesh; ${ }^{3}$ Department of Pathology, Jahurul Islam Medical College, \\ Kishoreganj, Bangladesh; ${ }^{4}$ Department of Community Medicine, Mugda Medical College, Dhaka,Bangladesh; \\ ${ }^{5}$ Communicable Disease Control, Directorate General of Health Services, Dhaka, Bangladesh; ${ }^{6}$ Department \\ of Community Medicine, Dhaka International Medical College, Dhaka, Bangladesh
}

\begin{abstract}
Background: Occupational stress is one of the key factors in reducing staff productivity in any organization with physical and psychological impacts on employees. Nursing is among the most stressful professions. Therefore, this study aimed to assess the extent of perceived level occupational stress and its association with work-related and non-work related variables as causes of stress and work ability among nurses in a Public Medical College Hospital.
\end{abstract}

Methods: A cross sectional study was done among nurses in Shaheed Suhrawardy Medical College Hospital (ShSMCH) during July 2015-June 2016 among 197 nurses, selected through a simple random sampling. Face to face interview was conducted, using a pretested semi-structured questionnaire. Occupational stress and work ability were measured using Expanded Nurses Stress Scale Questionnaire (ENSS) and Work Ability Index Questionnaire (WAIQ). Appropriate statistical analysis was performed to see the level of significance.

Results: Majority (69.0\%) of the study population were between the age of 21 to 39 years, $94.9 \%$ were female, $68.0 \%$ were married, $79.2 \%$ were Muslim, $84.3 \%$ had diploma, $91.4 \%$ family income were equal or more than $\mathrm{Tk} 40,000,95.5 \%$ did clinical work. Some $25.0 \%$ worked in medicine ward, $22.8 \%$ worked at surgery ward and $90.9 \%$ worked more or less than 50 hours per week. Only $5.1 \%$ found to be high stress and $94.6 \%$ low stress. Significant difference was found between female and male, occupational stress and religion, educational status, type of work, occupational stress and work ability $(p<0.05)$.

Conclusion: Severe occupational stress is associated with reduced work ability. So, it is recommended to decrease occupational stress to increase work ability, although identification of sources of occupational stress seems necessary in order to adopt appropriate stress management strategies.

Keywords: Occupational stress, ENSS, Work ability, WAIQ

\section{Introduction}

Nursing is generally perceived as demanding profession. Along with the increased demand and progress in the nursing profession, stress among the nurses has also increased. Nursing profession follows a holistic approach, taking into account the person in totality in his or her environment. Nurses provide presence, comfort, help and support for people confronted with loneliness, pain,

*Correspondence: Shila Rani Das, Department of Community Medicine, Z H Sikder Women Medical College, Dhaka, Bangladesh; e-mail: dr.shila@yahoo.com ORCID: https://orcid.org/0000-0002-8258-2803 incapacity, disease and even death. The fact that nursing has been extensively and unfailingly recognized worldwide as a stressful job is therefore not surprising. ${ }^{1}$ Stress is experienced when demands made on us outweigh our resources. Stress is the common phenomena being experienced by almost all individuals and it viewed as a real threat to the physiological and psychological response producing mental tension or physiological reactions leading to illness and which increases the demands for adjustment upon the individual. ${ }^{2}$ WHO defines occupational stress 
"is the response people may have when presented with work demands and pressures that are not matched to their knowledge and abilities and which challenge their ability to cope." 3 Work related stress is the response peoples may have when presented with work demands and pressures that are not matched to their knowledge and abilities and which challenges their ability to cope. There is often confusion between pressure or challenge and stress and sometimes it is used to excuse bad management practice. ${ }^{4}$ Workplace stress can impact on employee productivity through increased absenteeism and presentism but with reduced productivity imposing a direct economic cost on employers and the society. ${ }^{5}$ Work ability comprises physical, psychological, and social capacities. It is influenced by demographic, socio-economic, environmental and life style factors. Significant negative correlation between occupational stress and work ability. ${ }^{16}$ Now-a-days, one of the most important personnel management challenges is to explore factors that stimulate or hinder the development of individual work ability and quality of life throughout a career. Maintaining clinical nurses quality of life and work ability is an important issue because it is the foundation for the well-being of the workforce. $^{18}$ Therefore, occupational stress is considered a challenge for the employers and because high level stress results in low productivity and other employee problems it is necessary that managers find a way of addressing the issue of occupational stress. ${ }^{6}$ Nurses of public hospital of Bangladesh are indisputably challenging, because in daily basis they are facing multiple sources of stress and which affect their work ability. So, it is important to know how hospitals work and working environment affect nurses work ability and wellbeing. The present study was conducted to determine perceived level of occupational stress and its association with work and non-work related causes of stress and work ability among nurses.

\section{Materials and Methods}

A cross sectional study was done to assess the extent of perceived level occupational stress and its association with work-related and non-work related causes of stress among nurses in a Public
Medical College Hospital, Dhaka from July 2015 to June 2016. Study population was nurses of Shaheed Suhrawardy Medical College Hospital (ShSMCH). Nurses who were working in this hospital for at least one year fulfilled the inclusion criteria. Exclusion criteria were unpleasant or stressful events within the last six months such as the death of the spouse or close relatives, divorce or pregnancy during the study period. Sample size was calculated on the basis of expected prevalence of stress among nurses. Considering data calculated from previous different studies about $58 \%$ of prevalence of occupational stress provided highest sample size i.e 347 . $^{7}$ Study population was finite number that is 311 . So, the following formula was used:

$$
n=\frac{n_{0}}{1+\frac{n_{0}}{N}}
$$

Here, $\mathrm{n}=$ required Sample size $=$ ? , $\mathrm{n}_{0}=$ estimated sample $=347, \mathrm{~N}=$ finite population $=311$. After calculation, sample size was found to bebe 164. But it was assumed that inflation of the sample size by $20 \%$ would be accommodate for any withdrawal from participation or non-response at different stages of data collection. Based on the above consideration finally the sample size was decided to include $164+33=197$ study participants. Initially nurses were selected from employee list (sample frame) of 311 nurses working in different ward and unit of ShSMCH by simple random sampling. A total of 311 population were taken for the research. Among the study population finally 49 from medicine, 45 from surgery, 40 from gynae and obstretics, 32 from paedriatics, 31 from burn unit, ICU emergency were selected.

Data were collected by face to face interview with pretestedquestionnaire. The Questionnaire had three parts related to Work \& non- work related variables, Expanded Nurses Stress Scale Questionnaire, Work Ability Index Questionnaire. Original Expanded Nursing Stress Scale (ENSS) consists of a 57 items, in this study only 38 items found to be necessary after pre testing. In order to compute stress score, all 38 items added together which was ranged from 0 to 152 . Mild Level of Stress 0-38, Moderate Level of Stress 39-78, Severe Level of Stress 79-114, Very Severe Level of Stress 115-152. Then it was grouped to simplify 
the data analysis which was low stress (0-76) and high stress (77-152). Work ability was measured by the Work Ability Index Questionnaire. The Work Ability Index (WAI) developed by the Finnish Institute of Occupational Health (FIOH) is a questionnaire-based method assessing perceived work ability. The WAI score was calculated from answers to seven items: current work ability compared with the life time best, work ability in relation to the demands of the job, number of current diseases diagnosed by a physician, estimated work impairment due to diseases, sick leave during the past 12 months, personal prognosis of work ability two years from now, and mental resources. The WAI score ranged from 7 to 49 points. Higher scores indicate better work ability. WAI is considered poor in the range 7-27, moderate in the range 28-36, good in the range of 37-43, and excellent in the range 44-49. Analysis of data was done using "Statistical Package for Social Science" (SPSS) programme. Descriptive statistics like frequency distribution, mean, median, mode, range, standard deviation etc. were calculated by SPSS program. Assess relationship between two categorical variables by Pearson's Chi-square $\left(\chi^{2}\right)$ test and test $2 \times 2$ table at $p<0.05$ level of significance.

The ethical clearance was obtained from the Ethical Committee of the National Institute of Preventive and Social Medicine (NIPSOM). Before collection of data, permission was taken from authority of concerned department. Before interview, informed written consent was obtained from every employee. Confidentiality of data and privacy of participants were maintained strictly.

\section{Results}

Of the 197 nurses who participated in the study, $69.0 \%$ were age group 21 to 39 years, followed by 40 to 58 years $31.0 \%$ and their mean age was 35.9 $( \pm 8.01)$ years. Almost 94.9\% were female, $68.0 \%$ were married and $32 \%$ single. About $79.2 \%$ were Muslim and 20.8\% Non-muslim, $84.3 \%$ had diploma, $11.2 \%$ had B.Sc in nursing and $4.6 \%$ had post graduate degree. Monthly household income of the respondents ranged from $\mathrm{Tk} 30,000$ to 50,000 and their mean income was Tk $46751 \pm$ 4557, Majority (91.4\%) respondents' monthly household income was $\mathrm{Tk} 40,000$ and above and $8.6 \%$ had less than Tk 40,000. Almost 95.5\% respondents were involved in clinical work and $4.1 \%$ administrative works. Of them $24.9 \%$ of respondents worked in medicine, $22.8 \%$ in surgery, $20.3 \%$ in gynae and obstetrics, $16.2 \%$ at burn, emergency and ICU and $15.7 \%$ worked paedriatics wards. About $61.9 \%$ took training. About $57 \%$ worked 10 years or moreand $42.1 \%$ less than 10 years. Majority (52.8\%) worked in day shift, $30.5 \%$ and $16.8 \%$ worked in evening and night shift respectively. Almost $90.9 \%$ nurses were worked 50 hours or more per week.

Table I: Information regarding work related variables $(\mathrm{N}=197)$

\begin{tabular}{lcc}
\hline Type of work & (n) & $\mathbf{( \% )}$ \\
\hline Administrative & 8 & 4.1 \\
Clinical & 189 & 95.9 \\
Name of ward/unit & 49 & \\
Medicine & 45 & 24.9 \\
Surgery & 40 & 22.8 \\
Gynae and Obstretics & 31 & 20.3 \\
Burn unit, ICU, Emergency & 32 & 16.2 \\
Pediatrics & & 15.7 \\
Year of experience & 83 & \\
$<10$ years & 114 & 42.1 \\
$\geq 10$ years & 104 & 57 \\
Shift of work & 60 & 52.8 \\
Day Shift & 33 & 30.5 \\
Evening Shift & & 16.8 \\
Night Shift & 18 & \\
Hours of work per week & 179 & 9.1 \\
$<50$ & & 90.1 \\
$\geq 50$ & 75 & 38.1 \\
Training & 122 & 61.9 \\
No & $\mathbf{1 9 7}$ & $\mathbf{1 0 0}$ \\
Yes & & \\
\hline Total & & \\
\hline & &
\end{tabular}

Most of them (94.6\%) had been found to have low stress and $5.1 \%$ high stress.

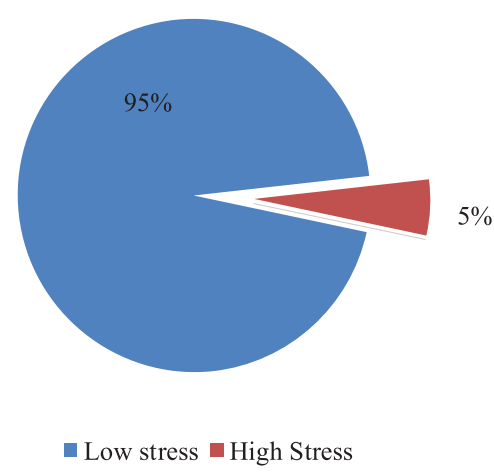

Figure 1: Distribution of Occupational stress level $(n=197)$ 
Almost 92.9\% respondents had good to excellent work ability and $7.1 \%$ had less good work ability.

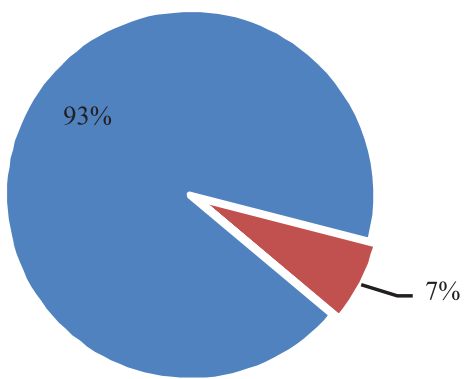

- Good to excellent work ability - Less good work ability

Figure 2: Distribution of work ability index category level

Significant association was observed between occupational stress level and gender.

Table II: Comparison of occupational stress score between sex

\begin{tabular}{ccccc}
\hline $\begin{array}{c}\text { Occupational } \\
\text { stress }\end{array}$ & Gender & N & Mean \pm SD & $\begin{array}{c}\boldsymbol{p} \\
\text { value }\end{array}$ \\
\hline \multirow{2}{*}{$0-152$} & Female & 187 & $52.68 \pm 9.94$ & \\
& Male & 10 & $64.7 \pm 15.35$ & $p=.03$ \\
\hline
\end{tabular}

Occupation stress was found more prevalent in Muslim, post graduate nurse and administrative workers (table III).

Table III: Association Between Occupational stress and religion and education level and type of job

\begin{tabular}{lccc}
\hline $\begin{array}{l}\text { Variables } \\
\text { Religion }\end{array}$ & \multicolumn{2}{c}{ Stress level } & $\begin{array}{c}\text { Comment } \\
\chi^{\mathbf{2}}, \mathbf{d f}=\mathbf{1}\end{array}$ \\
\cline { 2 - 3 } Muslim & Low stress & High stress & 5.446 \\
Non-muslim & $36(87.8 \%)$ & $59(12.2 \%)$ & $p=.02$ \\
Educational status & & & \\
Diploma & $161(97.6 \%)$ & $4(2.4 \%)$ & 14.606, \\
B.Sc in nursing & $21(87.5 \%)$ & $3(12.5 \%)$ & $p=.001$ \\
Postgraduate & $5(62.5 \%)$ & $3(37.5 \%)$ & \\
Type of job & & & \\
Administrative & $5(62.5 \%)$ & $3(37.5 \%)$ & 18.193 \\
Clinical & $182(96.3 \%)$ & $7(3.7 \%)$ & $p=.000$ \\
\hline
\end{tabular}

There was statistically significant association found between occupational stress and work ability index. $(p=0.000)$.

Table IV: Association between occupational stress and work ability

\begin{tabular}{ccccc}
\hline $\begin{array}{c}\text { Stress } \\
\text { level }\end{array}$ & \multicolumn{2}{c}{$\begin{array}{c}\text { Work ability index } \\
\text { category }\end{array}$} & Total & Sig. \\
\hline Low stress & $177(94.7 \%)$ & $10(5.3 \%)$ & $187(100 \%)$ & $\chi_{1}^{2}=17.266$ \\
High stress & $6(60 \%)$ & $4(40 \%)$ & $10(100 \%)$ & \\
Total & $183(92.9 \%)$ & $14(7.1 \%)$ & $197(100 \%)$ & $p=0.000$ \\
\hline
\end{tabular}

A: Good to excellent work ability

$\mathrm{B}$ : Less good work ability

\section{Discussion}

The present study was carried out to assess the extent of perceived level occupational stress and its association with work related and non-work related variables as causes of stress among nurses in a Public Medical College Hospital. The result showed $73.4 \%$ the age group 21 to 40 years which was not similar to the study conducted in India where $22.1 \%$ were younger than 30 years old, $59.6 \%$ were aged between $30-40$ years. ${ }^{8}$ Almost $94.60 \%$ were female which was similar to other study where $93 \%$ female. ${ }^{9}$ About $68 \%$ nurses were married which was not similar $80.4 \%$ to the study conducted in India. ${ }^{10}$ Majority of the respondents $84.3 \%$ were had professional degree of diploma in nursing, $11.2 \%$ had BSc in nursing and $4.6 \%$ had post graduate degree which was not similar with the study of Jordan, where $90 \%$ bachelor and $5 \%$ post graduate. ${ }^{11}$ Almost $91.4 \%$ of the respondents monthly household income were more than $\mathrm{Tk}$ 40,000 with a mean of the $46751 \pm 4557 \mathrm{Tk}$. which was not similar to the study done in Bangladesh, where $74.8 \%$ monthly more than $\mathrm{Tk}$ $40,000 .{ }^{12}$ About $24.9 \%$ worked in medicine ward, $22.8 \%$ worked at surgery ward, $20.3 \%$ worked in gynae and obstetrics ward, 16.2\% worked at burn, emergency and ICU unit and $15.7 \%$ worked in paedriatics which was not similar to the study done in Uganda where $35.14 \%$ worked in medicine, $17.1 \%$ in surgery, $30.6 \%$ in obstetrics/gynecology wards. ${ }^{13}$ Almost $95.5 \%$ of respondents were done mainly clinical job and $4.1 \%$ were do administrative works. Majority $61.9 \%$ had training related to job and $38.1 \%$ had no trained. Most $57.0 \%$ of the respondents' experiences of work were more than 10 years and $42.1 \%$ less than 10 years. Mean year of experience was $12.55 \pm 4.80$ years which was not similar to the study done in India where $44 \%$ having more than 10 year of experience and $56 \%$ had less than 10 years. $^{14}$ About $52.8 \%$ worked in day shift, $30.5 \%$ and $16.8 \%$ of the respondents worked in evening and night shift respectively. Almost $90.9 \%$ of the nurses were found to work within 50 hours or more per week and $9.1 \%$ less than 50 hours of work per week. Only $5.1 \%$ found to be high stress and majority $94.6 \%$ respondents had been found to have low stress. But in another study which was done in India found that $42 \%$ had high stress and $48.0 \%$ had low stress. ${ }^{15}$ Most of the (92.9\%) respondents had good to excellent work ability and $7.1 \%$ had less good work ability. This 
was not similar to the study done in Iran where $98.8 \%$ and $0.8 \%$ of the subjects showed good to excellent and poor work abilities, respectively. ${ }^{16}$ Significantly difference was found between female $(52.68 \pm 9.94)$ and male $(64.7 \pm 15.35) p=.000$ and the study was similar to the finding of study done in Saudi Arabia where $77 \%$ were female and $23 \%$ male nurses and significant statistical differences in perceived job related stress due to gender $p=.038 .^{17}$ Occupational stress was found more prevalent in Muslim, post graduate nurse, administrative workers. This study was not similar to study done by Shivaprasad. But no significant association between education and occupational stress in study done by. ${ }^{13}$ Majority $94.7 \%$ respondents had good to excellent work ability those who had low stress and $60 \%$ respondents had good to excellent work ability those who had high stress and statistically significant association was found between occupational stress and work ability index. $(p<0.05)$ which was not congruent to study by Kordi. They showed no significant association between Occupational stress and Work ability $(p>0.05){ }^{16}$

\section{Conclusion}

According to the findings of the study, social and professional support should be provided to reduce high stress and increase work ability. Further studies are suggested to identify nurses, who are at risk of severe stress level and low work ability for effective interventions.

Conflict of interest: No conflict of interest.

\section{References}

1. Gulavani A and Shinde M. Occupational Stress and Job Satisfaction among Nurses. International Journal of Science and Research. 2014;3, 733-40.

2. Yadav N. and Kiran U.V. Occupational Stress among Security Guards. Journal for Studies in Management and Planning. 2015; 1:21-31

3. World Health Organization, Occupational stress in the care of the critically ill, the dying and the bereaved, Hemisphere Publishing Coporation, 2014.

4. Semmer Nk. Stress at the workplace, World Health Organization, 2007.

5. Yong $\mathrm{M}$, Nasterlack $\mathrm{M}$, Pluto. $\mathrm{R} \mathrm{P}$, Lang $\mathrm{S}$ and Oberlinner C. Occupational stress perception and its potential impact on work ability. Work. 20131 ; 46:347-54.

DOI: doi.org/10.3233/WOR-121556
6. Elovainio. (2002) Worksite Stress Management Interventions: Their Effectiveness and Conceptualisation, Journal of Managerial Psychology. 2002; 2:4-10.

7. Wilkins, K. (2007) 'Work stress among health care providers Work stress among health care providers Work stress among health care providers', Health Reports. 2007; 18:33-36.

8. Saleh AM, Saleh MM and AbuRuz ME. The impact of stress on job satisfaction for nurses in King Fahad Specialist Hospital-Dammam-KSA, Journal of American Science. 2013;371-77.

9. Megrath. A, Reid. N, Boore J. Occupational stress in nursing', International, Journal of Nursing Studies, 2003; 40: 555-65.

DOI: doi.org/10.1016/S0020-7489(03)00058-0.

10. Bhatia N, Kishore J, Anand T. and Jiloha R C. Occupational Stress Amongst Nurses from Two Tertiary Care Hospitals in Delhi, Australasian Medical Journal. 2010; 3:731-38. DOI: doi.org/10.4066/AMJ.2010.289

11. AbuRu ME, Comparative study about the impact of stress on job satisfaction between Jordanian and Saudi nurses, European Scientific Journal. 2014; $10: 167$.

12. Munir UR. Occupational Stress in Health Professionals of Selected Combined Military Hospital, M Phil thesis, NIPSOM, Mohakhali. 2014.

13. Chalo NR. Occupational stress job satisfaction and job performance among hospital nurses in Kampala Uganda, 2010: 06. J Nurs Manag.2011;19: 760-68.

14. Mohite M. Shinde M. Gulavani A. Occupational Stress among Nurses Working At Selected Tertiary Care Hospitals, International Journal of Science and Research. 2014; 3.

15. Shivaprasad AH. Work related stress of nursing, Journal of Psychiatry Nursing. 2013; 2: 53-59.

16. Kordi M. Mohamadirizi S. Shakeri MT. Gharavi MM. and Fadardi JS. Relationsehip between Occupational Stress and Work Ability of Midwives in Mashhad, Journal of Midwifery and Reproductive Health. 2011; 2: 188-94.

17. Kamal SM. Al-Dhsham M, Abu-Salameh KA, Abuadas FH and Hassan M.M. The effect of nurses Perceived Job Related Stressors on Job Satisfaction in Taif Governmental Hospitalsin Kingdom of Saudi Arabia, Journal of American Science. 2012; 8: 119-25.

18. Milutinovic, D. Golubovic, B. Brkic, N. and Prokes, B. 'Professional stress and health among critical care nurses in Serbia. Arhhig Rada Toksikol. 2012:63:171-80. DOI: doi.org/10.2478/10004-1254-63-2012-2140. 